\title{
Characterization of two children with tetrasomy 18p syndrome through multiplex ligation-dependent probe amplification and single nucleotide polymorphism-array: expanding phenotype?
}

\author{
Jaime Toral-López¹, Luz M. González-Huerta², Mirna Martínez-Saucedo³, Olga Messina-Baas², \\ Juan Manuel-Valdes², and Sergio A. Cuevas-Covarrubias* \\ ${ }^{1}$ Department of Medical Genetic, Centro Médico Ecatepec, Instituto de Seguridad Social del Estado de México y Municipios, Ecatepec, State of \\ Mexico; ${ }^{2}$ School of Medicine, Universidad Nacional Autónoma de México, Mexico City; ${ }^{3}$ Deparment of Gentetics, Hospital Infantil de México, \\ Federico Gómez, Mexico City. Mexico
}

\begin{abstract}
Tetrasomy $18 p$ is characterized by intellectual disability and systemic alterations. The aim of this study is to describe two patients with tetrasomy $18 p$, one of them with clinical data not previously reported. Genomic DNA was analyzed by multiplex ligation-dependent probe amplification and single nucleotide polymorphism-array. The final molecular result for each of the patients was arr (hg19) 18p11.32-p11.21 (136.226-15,157.836) $\times 4$ dn and arr (hg19) 18p11.32-p11.21 (134,878, -15,149,748) $\times 4 \mathrm{dn}$. The results of both parents were normal. Both patients showed data compatible with tetrasomy 18p. However, one patient presented atopic dermatitis, café-au-lait spots, and thyroglossal cysts. This data have not been reported in patients with tetrasomy $18 p$ before.
\end{abstract}

Key words: Tetrasomy 18p. Multiplex ligation-dependent probe amplification. Single nucleotide polymorphism-array.

\section{Introduction}

Tetrasomy $18 \mathrm{p}$ or isochromosome 18p (OMIM; $614290)$ is a rare chromosomal disorder with a prevalence of 1:140,000-180,000 live births ${ }^{1}$. At present, more than 200 cases have been described in the literature ${ }^{2,3}$. Approximately $30 \%$ are familial cases and only few cases have been reported as mosaics ${ }^{2}$. In most cases, the origin of tetrasomy $18 p$ is due to maternal non-disjunction during meiosis II, followed by poor centromere division. Maternal age may play a role in the formation of tetrasomy $18 p^{4}$. The marker chromosome is an abnormal small chromosome fragment that we can find when performing a karyotype, it has an incidence of $0.14-0.72 / 1000$ births, and many of them correspond to acrocentric chromosomes ${ }^{5}$. Multiplex ligation-dependent probe amplification (MLPA) is a variation of the multiplex polymerase chain reaction that allows multiple regions of the genome to be amplified at the same time ${ }^{6}$. The purpose of this study is to report on the MLPA and single nucleotide polymorphism (SN$\mathrm{P})$-array based molecular analysis of a chromosomal marker in two children that were born with tetrasomy 18p. Interestingly, we observed atopic dermatitis, caféau-lait spots (CALS), and a thyroglossal cyst in one patient. These clinical features have not been previously reported concerning this condition, which could indicate that they are clinical data associated with this syndrome.
Correspondence:

*Sergio Cuevas-Covarrubias

E-mail: sergiocuevasunam@gmail.com
Available online: 22-01-2021
Date of reception: 20-02-2020

Date of acceptance 13-03-2020

DOI: 10.24875/HGMX.20000037
Rev Med Hosp Gen Mex. 2021;84(1):36-40 www.hospitalgeneral.mx NC-ND license (http://creativecommons.org/licenses/by-nc-nd/4.0/) 


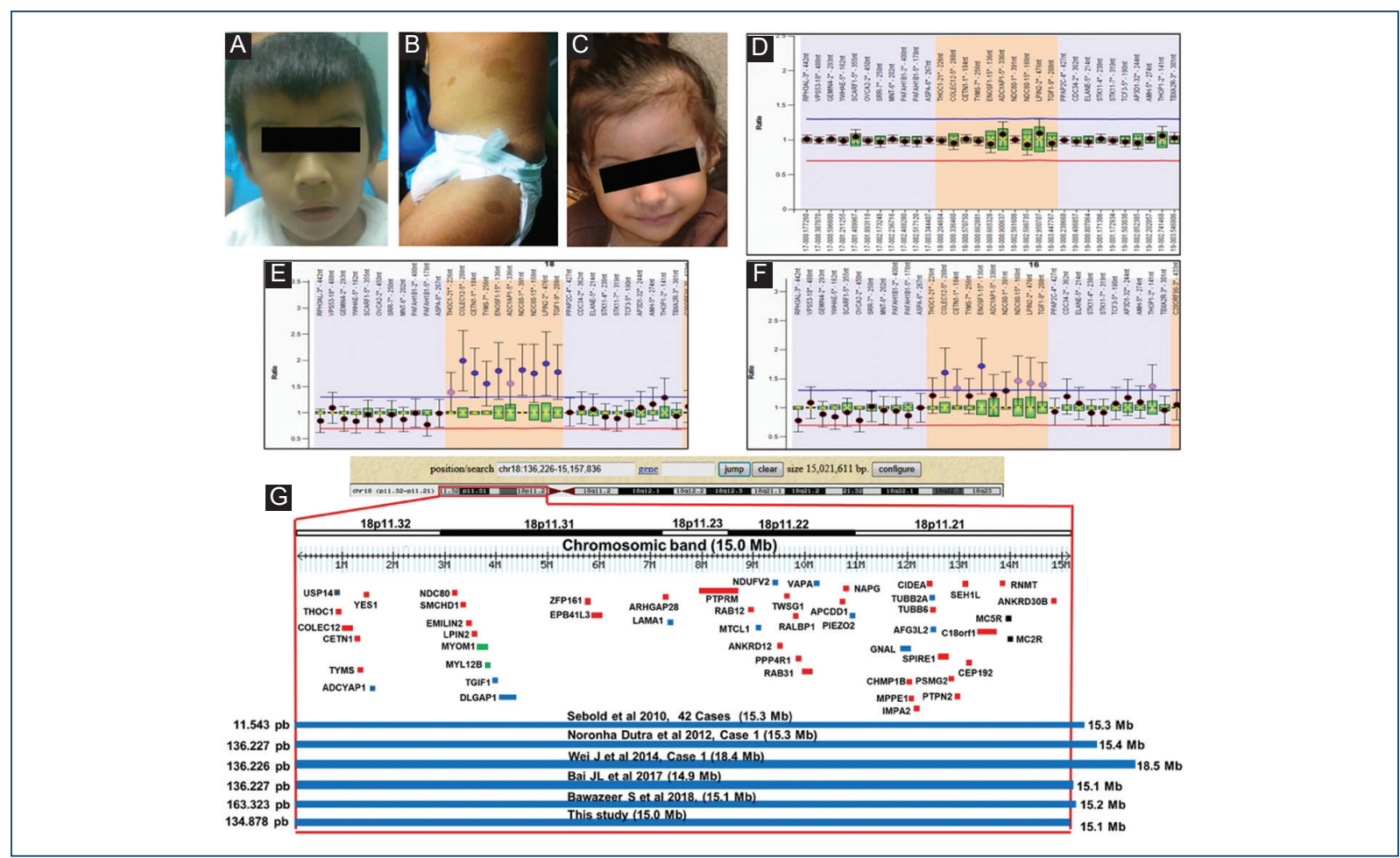

Figure 1. Characteristics of the patients. A-B: patient 1 at the age of 3 years and 5 months. C: patient 2 at the age of 2 years. Café au lait spots in patient. D: multiplex ligation probe amplification (MLPA) of health control. E-F: case 1 and case 2. G: representation of the CytoScan HD result, the figure shows the chromosome 18p11.32p11.21 and the relative position of the genes (USP14, ADCYAP1, DLGAP1, LAMA1, MTCL1, NDUFV2, VAPA, PIEZ02, TUBB2A, AFG3L2, GNAL) involved with the nervous system (blue). The OMIM genes are shown in red. Some affected patients with suppression in the $18 p 11.32 p 11.21$ region are also shown.

\section{Patient 1}

A male patient, 3 years and 10 months old, the third child of healthy, non-blood related parents. The mother was 35 years old and the father was 36 years old at the time of birth. Family history was negative for intellectual disability or congenital malformations. No history of prenatal exposure to teratogens or maternal diseases was recorded. After an uneventful pregnancy, the child was born by caesarean section at 40 weeks of gestation with

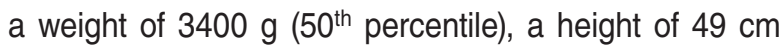
$\left(50^{\text {th }}\right.$ percentile), and a head circumference of $35 \mathrm{~cm}$ ( $50^{\text {th }}$ percentile). Apgar score was 8-9 and did not require special neonatal management. The child's growth and development were delayed, with the child holding its head up at the age of one, being able to remain in seated position at 2 years and it does not recognize receptive or expressive language. The mother reports that her child is very frightened indoors and often gets sick of the airways. From the child's birth to 6 months, he presented atopic dermatitis which has been decreasing.
On physical examination, his weight was $14,000 \mathrm{~g}$ (10-25 th percentile), height was $104 \mathrm{~cm}\left(75^{\text {th }}\right.$ percentile), and head circumference was $49 \mathrm{~cm}\left(25-50^{\text {th }}\right.$ percentile). His head is dolichocephalic with prominent forehead, low set ears, depressed nasal bridge with bulbous tip, palpebral fissures slightly downwards, prominent chest, modified single palmar crease on the left hand, bilateral cryptorchidism, five CALS on the abdomen, and thigh and leg more than $1 \mathrm{~cm}$ wide (Fig. 1A and B). The cranial tomography showed cerebral cortical atrophy and the ultrasound scan detected a thyroglossal cyst. Due to cryptorchidism, orchidopexy was performed at the age of 2 .

\section{Patient 2}

Female patient, 2 years old, the first child of healthy, non-blood related parents. The mother was 36 years old and the father was 33 years old at the time of birth. Family history was negative for intellectual disability or congenital malformations. No history of prenatal exposure to 
teratogens or maternal diseases was recorded. The mother had two threatened abortions in the first trimester and pre-eclampsia in the last trimester. Obstetric ultrasound showed delayed intrauterine growth. She was born by cesarean section at 37 weeks of gestation with a weight of $2780 \mathrm{~g}$ ( $10^{\text {th }}$ percentile), height of $49 \mathrm{~cm}\left(50^{\text {th }}\right.$ percentile), head circumference of $33 \mathrm{~cm}\left(10^{\text {th }}-25^{\text {th }}\right.$ percentile), and Apgar score of 8-9. The neonatal period was normal. The child's growth and development were delayed, with the child holding its head up at the age of 9 months, being able to remain in seated position at 1 year and 3 months and monosyllable speech at 1 year and 5 months. The child is not able to say complete sentences and does not walk. During physical examination, her weight was $8800 \mathrm{~g}$ (percentile < 3), height of $90 \mathrm{~cm}$ $\left(90^{\text {th }}\right.$ percentile), cephalic perimeter of $43.5 \mathrm{~cm}$ (percentile $<3$ ), microcephaly, ear length measurement within set limits, small palpebral fissures, and convergent strabismus (Fig. 1C). Transfontanellar ultrasound and brain MRI showed frontal cortical atrophy. Renal ultrasound detected right renal hypoplasia.

\section{Materials and methods}

The karyotype test was performed in metaphase from cultures of peripheral blood lymphocytes of the patients and their parents with standard methodology for GTG banding ( $\varangle 500$ bands). MLPA reaction was performed using the SALSA MLPA kit P290-B2 and P249 (MRC-Holland, Amsterdam, Netherlands) following supplier instructions. The results were analyzed with the Coffalyser software (MRC-Holland, Amsterdam, Netherlands). The SNP-array analysis was carried out using the CytoScan HD matrix (SNP-array) following the protocol provided by the supplier (Affymetrix, Santa Clara, California, USA). The SNP-array was scanned with the Affymetrix GeneChip Scanner $30007 \mathrm{G}$, and the data were analyzed with GTYPE (GeneChip Genotyping Analysis Software, version 1.0.12) to detect aberrations in the number of copies. The resolution of this procedure was estimated at $1.15 \mathrm{~kb}$. The Research Committee of the Institution approved the protocol and the parents gave their informed consent for the participation in the study.

\section{Results}

The results of the conventional karyotype test were 47, $\mathrm{XY},+$ mar for case 1 and $47, \mathrm{XX},+$ mar for case 2. The parents' karyotype tests were normal. The characterization of the marker chromosomes was first analyzed with
MLPA. It showed a higher copy number of the $18 p$ THOC1 probe (18p11.32) with the SALSA MLPA kit P290-B2 for both patients, and showed a higher copy number of probes COLEC12, CETN1, TYMS, ENOSF1, ADCYAP1, NDC80, LPIN2, and TGIF1 with the SALSA MLPA kit P249 (Fig. 1D-F). The CytoScan HD array showed a $15 \mathrm{Mb}$ amplification of 18p11.32-p11.21, with 78 RefSeq genes in the genomic variation database, DGV database (http://projects.variation.tcag.ca/variation/ hg38/). There are 52 genes listed in the OMIM database (Fig. 1G). The final cytogenetic result for the patients was 46, XY, arr [hg19] 18p11.32-p11.21 (136,226-15,157,836) $\times 4$ dn y 46, XX, arr [hg19] 18p11.32- p11.21 (134,878, $-15,149,748) \times 4 \mathrm{dn}$. Parental studies showed normal results.

\section{Discussion}

In the present study, two children are described with craniofacial dysmorphism, psychomotor retardation, significant language delay, short stature, and cortical atrophy due to tetrasomy $18 \mathrm{p}$. Both patients presented marker chromosomes identified by GTG banding; MLPA analysis showed the amplification of the short arm of chromosome 18 and the SNP-array analysis delimited the tetra-amplification of 18p.

At present, only few cases with tetrasomy $18 p$ have been analyzed with MLPA and SNP-array ${ }^{1,3,7-10}$. Previous analysis of a group of patients with tetrasomy $18 p$ identified that the first ten characteristics in these patients were developmental delay, intellectual disability, abnormal muscle tone, feeding difficulties, variants in brain MRI, microcephaly, strabismus, cryptorchidism, scoliosis/kyphosis, constipation, and growth retardation 1 . Heart, neural tube closure, and palatal defects were also observed to a lesser extent. Characteristics such as retrognathia, articular contraction of the limbs, and hypoplastic nails have also been described. Microcephaly, oval face, strabismus, small nose, low set ears, constipation, anomalies in the left foot, cryptorchidism, tendency to aggression, and autism were observed as symptoms in a 5-year-old boy with tetrasomy $18 p^{7}$. Our patient 2 showed similar characteristics to those reported; however, patient 1 showed atopic dermatitis, CALS and a thyroglossal cyst. This data had not been previously reported, which we deemed likely to be part of the clinical condition.

In the case of molecular analysis, the amplification of $15.0 \mathrm{Mb}$ at $18 \mathrm{p}$ included 52 genes listed in the OMIM database, 12 of which are related to the nervous system and may have some impact on the phenotypic 
characteristics of patients. The MC2R gene is expressed in the skin and can play a role in the pathophysiology of the skin ${ }^{11}$, such as the CALS observed in our patient. The product of the USP14 gene is involved in the degradation of proteasome substrates, can regulate synaptic activity and is related to Huntington's disease, affective disorders, and schizophrenia ${ }^{12}$. The PACAP gene is expressed in lateral ventricles, dentate line and hypothalamus producing the proliferation of nervous system cells, and has been associated with changes in sensitivity, learning and olfactory aspects ${ }^{13}$. The TGIF gene is related to the development of brain disease and has been observed to be expressed in the cortex of mice ${ }^{14}$. The DLGAP gene is expressed in synaptic sites of hippocampal dendritic spine and cerebral cortex of mice $^{15}$. The MTCL1 gene is related to the packaging and stabilization of microtubules in neurons ${ }^{16}$. The LAMA1 gene is related to intellectual disability and speech delay, as well as cysts and cerebellar atrophy, myopia, retinal dystrophy, and abnormal eye movement in Poretti-Boltshauser syndrome ${ }^{17}$. The NDUFV2 gene has been associated with encephalopathy, hypertrophic cardiomyopathy, and truncal hypotonia ${ }^{18}$. The VAPA gene is highly expressed in the brains of mice with unknown function ${ }^{19}$. The PIEZO2 gene has a role in electrical conduction that is mechanically activated in somatosensory neurons in the dorsal root ganglia; its defects have been related to Marden-Walker syndrome and distal arthrogryposis ${ }^{20}$. The GNAL gene is expressed in the basal ganglia, caudal nuclei, and in the amygdala and is associated with dystonia ${ }^{21}$. The TUBB2A gene has been associated with the phenotype of cerebral cortical dysplasia and other malformations while the AFG3L2 gene is related to cerebellar ataxia, dystonia, myoclonic epilepsy, oculomotor apraxia, and decreased ambulation ${ }^{22,23}$. It is worth mentioning that it is important to carry out more molecular studies of the nervous system genes to determine their participation in the phenotype of patients with tetrasomy $18 p$.

\section{Conclusion}

The present study describes two patients with tetrasomy $18 p$ by MLPA and SNP-array analysis, with a previous diagnosis of chromosomal marker by conventional karyotype test. We observed new previously unreported characteristics in one of the patients with tetrasomy $18 \mathrm{p}$. We also emphasize the importance of easy and fast molecular analysis of the marker chromosomes by MLPA.

\section{Conflicts of interest}

The authors declare have not any conflicts of interest.

\section{Acknowledgments}

The authors thank the support granted by DGAPA, PAPIIT project IN219419, Universidad Nacional Autónoma de México (UNAM).

\section{Ethical disclosures}

Protection of human and animal subjects. The authors declare that no experiments were performed on humans or animals for this study.

Confidentiality of data. The authors declare that they have followed the protocols of their work center on the publication of patient data.

Right to privacy and informed consent. The authors have obtained the written informed consent of the patients or subjects mentioned in the article. The corresponding author is in possession of this document.

\section{References}

1. Sebold C, Roeder E, Zimmerman M, Soileau B, Heard P, Carter E, et al. Tetrasomy 18p: report of the molecular and clinical findings of 43 individuals. Am J Med Genet A. 2010;152A:2164-72.

2. Dundar M, Caglayan AO, Saatci C, Cetin Z, Arslan K, Uzak AS. Formation of supernumerary euchromatic short arm isochromosomes: parent and cell stage of origin in new cases and review of the literature. Genet Couns. 2010;21:69-74

3. Dutra AR, Mancini TI, Takeno S, Oliveira MM, Kim CA, Perez AB, et al. Different conformation of two supernumerary $18 p$ isochromosomes, one with a concomitant partial 18q trisomy. Cytogenet Genome Res. 2012; 138:1-4.

4. Eggermann T, Schubert R, Engels H, Apacik C, Stengel-Rutkowski S, Haefliger $\mathrm{C}$, et al. Formation of supernumerary euchromatic short arm isochromosomes: parent and cell stage of origin in new cases and review of the literature. Ann Genet. 1999;42:75-80.

5. Jafari-Ghahfarokhi H, Moradi-Chaleshtori M, Liehr T, Hashemzadeh-Chaleshtori M, Teimori H, Ghasemi-Dehkordi P. Small supernumerary marker chromosomes and their correlation with specific syndromes. Adv Biomed Res. 2015:4:140.

6. Os PG, Schouten JP. Multiplex ligation-dependent probe amplification (MLPA囚) for the detection of copy number variation in genomic sequences. Methods Mol Biol. 2011;688:97-126.

7. Wei J, Xie Y, He W, Liu W, Jian W, Chen M, et al. Clinical outcome: a monosomy $18 p$ is better than a tetrasomy $18 p$. Cytogenet Genome Res. 2014;144:294-8.

8. Balasubramanian M, Sithambaram S, Smith K. Inherited duplication of the short arm of chromosome 18p11.32-p11.31 associated with developmental delay/intellectual disability. Clin Dysmorphol. 2016;25:19-22.

9. Bai JL, Jin YW, Qu YJ, Wang H, Cao YY, Song F. Mosaicism of tetrasomy 18p: clinical and cytogenetic findings in a female child. Chin Med J (Engl). 2017;130:744-6

10. Bawazeer S, Alshalan M, Alkhaldi A, AlAtwi N, AlBalwi M, Alswaid A, et al. Tetrasomy 18p: case report and review of literature. Appl Clin Genet. 2018;11:9-14.

11. Slominski A, Ermak G, Mihm M. ACTH receptor, CYP11A1, CYP17 and CYP21A2 genes are expressed in skin. J Clin Endocrinol Metab. 1996;81:2746-9.

12. VerPlank JJ, Lokireddy S, Feltri ML, Goldberg AL, Wrabetz L. Impairment of protein degradation and proteasome function in hereditary neuropathies. Glia. 2018:66:379-95.

13. Oride A, Kanasaki $H$, Kyo S. Role of pituitary adenylate cyclase-activating polypeptide in modulating hypothalamic-pituitary system. Reprod Med Biol. 2018;17:234-41. 
14. Wotton D, Taniguchi K. Functions of TGIF homeodomain proteins and their roles in normal brain development and holoprosencephaly. Am J Med Genet C Semin Med Genet. 2018;178:128-39.

15. Rasmussen AH, Rasmussen HB, Silahtaroglu A. The DLGAP family: neuronal expression, function and role in brain disorders. Mol Brain 2017;10:43

16. Satake T, Yamashita K, Hayashi K, Miyatake S, Tamura-Nakano M, Doi H, et al. MTCL1 plays an essential role in maintaining Purkinje neuron axon initial segment. EMBO J. 2017;36:1227-42.

17. Micalizzi A, Poretti A, Romani M, Ginevrino M, Mazza T, Aiello C, et al. Clinical, neuroradiological and molecular characterization of cerebellar dysplasia with cysts (Poretti-Boltshauser syndrome). Eur J Hum Genet. 2016;24:1262-7.

18. Liu HY, Liao PC, Chuang KT, Kao MC. Mitochondrial targeting of human NADH dehydrogenase (ubiquinone) flavoprotein 2 (NDUFV2) and its association with early-onset hypertrophic cardiomyopathy and encephalopathy. J Biomed Sci. 2011;18:29.
19. Kirmiz M, Vierra NC, Palacio S, Trimmer JS. Identification of VAPA and VAPB as Kv2 channel-interacting proteins defining endoplasmic reticulum-plasma membrane junctions in mammalian brain neurons. J Neurosci. $2018: 38: 7562-84$

20. McMillin MJ, Beck AE, Chong JX, Shively KM, Buckingham KJ, Gildersleeve HI, et al. Mutations in PIEZO2 cause Gordon syndrome, Marden-Walker syndrome, and distal arthrogryposis Type 5. Am J Hum Genet. 2014:94:734-44.

21. Masuho I, Fang M, Geng C, Zhang J, Jiang H, Özgul RK, et al. Homozygous GNAL mutation associated with familial childhood-onset generalized dystonia. Neurol Genet. 2016;2:e78.

22. Sferra A, Fattori F, Rizza T, Flex E, Bellacchio E, Bruselles A, et al. Defective kinesin binding of TUBB2A causes progressive spastic ataxia syndrome resembling sacsinopathy. Hum Mol Genet. 2018;27:1892-904.

23. Coutelier M, Coarelli G, Monin ML, Konop J, Davoine CS, Tesson C, et al. A panel study on patients with dominant cerebellar ataxia highlights the frequency of channelopathies. Brain. 2017;140:1579-94. 